\section{Managing acute promyelocytic leukemia in patients belonging to the Jehovah's Witness congregation}

\author{
Anand P. Jillella, ${ }^{1}$ Martha L. Arellano, ${ }^{1}$ \\ Leonard T. Heffner, ${ }^{1}$ Manila Gaddh, ${ }^{1}$ \\ Amelia A. Langston, ${ }^{1}$ \\ Hanna J. Khoury, ${ }^{1}$ \\ Abhishek Mangoankar, ${ }^{2}$ \\ Vamsi K. Kota ${ }^{1}$ \\ ${ }^{1}$ Department of Hematology and \\ Medical Oncology, Winship Cancer \\ Institute of Emory University, Atlanta, \\ GA; ${ }^{2}$ Department of Medicine, Georgia \\ Regents University, Augusta, GA, USA
}

\begin{abstract}
Acute promyelocytic leukemia (APL) is a hyper-acute leukemia and presents with cytopenias and disseminated intravascular coagulation. Jehovah's Witnesses with APL offer a unique challenge during induction by refusing transfusion and pose a difficult challenge in this curable disease. Our focus over the last 8 years has been decreasing early deaths in APL in both academic and community centers. As a result we have extensive experience in APL induction with a proven improvement in early deaths. Three patients with APL belonging to the Jehovah's Witness congregation were treated in our practice and published literature in treating Witnesses with APL was reviewed. It is highly imperative to prevent induction mortality in this patient population. The goal of treatment among the Witnesses is to prevent death during induction and subsequently cure them. We discuss the management and proactive measures to prevent induction mortality in this most curable blood cancer.
\end{abstract}

\section{Introduction}

Patients belonging to the Jehovah's Witness congregation refuse blood transfusions resulting in specific challenges to the health care team especially in diseases with good outcomes. The belief is based on their interpretation of the scripture that forbids eating of blood; these passages have been interpreted as precluding transfusion of blood. ${ }^{1}$ Acute promyelocytic leukemia (APL) commonly presents with profound cytopenias and an aggressive strategy of blood product transfusion is the mainstay of supportive care during induction. This results in both practical as well as ethical problems during leukemic induction. Witnesses have been treated without blood product support during induction period of acute leukemias including APL induction and have also successfully received autologous and allogeneic transplants. ${ }^{2-4}$

Excellent drugs are available to treat APL; specifically those that are mildly suppressive thereby limiting the need for transfusion support. This is an ideal leukemia where these agents along with growth factors developed for different blood lines; and supportive care could be judiciously used. This will eliminate the need for transfusions during treatment. However the consistent problem in APL across the general population is a high early death rate of approximately $30 \%$ during induction. ${ }^{5,6}$ The main causes of death during induction are bleeding, differentiation syndrome, infection and multi-organ failure. We treated three Witnesses with APL and herein report our experience. We also reviewed the literature on APL induction and identified a scant amount of data. It is likely that patients with negative outcomes were not reported resulting in limited available data. From reviewing the APL literature in Witnesses (similar to APL in general), patients who survived induction achieved hematologic and molecular remission and in all likelihood cured. As such preventing induction mortality in this patient population is the most critical aspect of management.

\section{Materials and Methods}

We performed a Pubmed search to include acute promyelocytic leukemia and Jehovah's Witness. Published literature on leukemias, cancers, supportive care in Jehovah's Witness patients was reviewed. ${ }^{3,7-11}$ Our own experience in treating three APL Jehovah Witness patients is also documented.

\section{Case Report \#1}

A 71 year old female with hypertension and diabetes presented in 2013 with a white blood cell (WBC) count of $10 \times 10^{9} / \mathrm{L}$, Hemoglobin $(\mathrm{Hb})$ of $6.6 \mathrm{~g} / \mathrm{dL}$ and platelets $7 \times 10^{9} / \mathrm{L}$, fibrinogen $107 \mathrm{mg} / \mathrm{dL}$ and markedly elevated D-dimers. After confirmation of the diagnosis of APL, Al-trans retinoic acid (ATRA) at $45 \mathrm{mg} / \mathrm{m}^{2}$ and arsenic trioxide (ATO) $0.15 \mathrm{mg} / \mathrm{kg}$ were started. Patient accepted cryoprecipitate but refused packed red cells and platelets. Erythropoietin at 40,000 units once a day was given as well as dexamethasone $10 \mathrm{mg}$
Correspondence: Vamsi Kota, Department of Hematology and Medical Oncology, Winship Cancer Institute of Emory University, Atlanta, GA 30322, USA.

Tel.: +1.404.778.1923 - Fax: +1.404.778.5048.

E-mail: vkota@emory.edu

Key words: Acute Promyelocytic leukemia; Jehovah Witness; Early deaths.

Contributions: AJ, MA, VK designed the concept, LTH, AL, MG, HK, AM, provided patient information and all authors were involved in writing and reviewing the manuscript.

Conflict of interest: The authors declare no potential conflict of interest.

Received for publication: 23 February 2017 Revision received: 7 June 2017.

Accepted for publication: 11 June 2017.

This work is licensed under a Creative Commons Attribution-NonCommercial 4.0 International License (CC BY-NC 4.0).

(C) Copyright A.P. Jillella et al., 2017

Licensee PAGEPress, Italy

Hematology Reports 2017; 9:7083

doi:10.4081/hr.2017.7083

IV twice a day. On day 4 of admission, the patients $\mathrm{Hb}$ decreased to $3.6 \mathrm{~g} / \mathrm{dL}$, became progressively weaker, unresponsive and died on day 7 .

\section{Case Report \#2}

A 56 year old Hispanic female presented with flu-like symptoms and was treated with oseltamivir in late 2013. Two weeks later patient was found to have a DVT and heparin therapy was started. The patient was also pancytopenic with a WBC of $0.8 \times 10^{9} / \mathrm{L}, \quad \mathrm{Hb} 11.8 \mathrm{~g} / \mathrm{dL}$, platelets $47 \times 10^{9} / \mathrm{L}$, INR 1.7 , Fibrinogen $132 \mathrm{mg} / \mathrm{dL}$, D-dimers 5463 (normal <295); a diagnosis of APL was made. ATRA at $45 \mathrm{mg} / \mathrm{M}^{2}$ per day was started, an IVC filter placed and heparin was stopped. The patient accepted cryoprecipitate but no other blood products. Arsenic Trioxide was started on day 3 at $0.25 \mathrm{mg} / \mathrm{kg}$ twice a week. Blood draws were restricted to once a day initially and subsequently twice a week. On day 10, ATO was held for a rising white count of $10 \times 10^{9} / \mathrm{L}$ and darbepoetin started for $\mathrm{Hb}$ of $8.8 \mathrm{~g} / \mathrm{dL}$. Hydroxyurea was started for a WBC of $39.8 \times 10^{9} / \mathrm{L}$ on day 16 and ATO restarted on day 21 with a $30 \%$ dose reduction three times a week. Day $24 \mathrm{Hb}$ dropped 
to $7.9 \mathrm{~g} / \mathrm{dL}$ with angina; darbopoetin was switched to erythropoietin (EPO) with oral iron supplementation. On day $37 \mathrm{WBC}$ increased $2.6 \times 10^{9} / \mathrm{L}, \mathrm{Hb} 10.2 \mathrm{~g} / \mathrm{dL}$ and platelets $183 \times 10^{9} / \mathrm{L}$ and she was discharged. The patient completed 4 cycles of ATO and ATRA based consolidation and is in molecular remission one year post treatment.

\section{Case Report \#3}

A 59 year old white female was admitted in mid-2014 with a 2 week history of aches and pains, shortness of breath, fevers and headache. A CT scan of the head showed multiple acute infarcts. The WBC was $38.6 \times 10^{9} / \mathrm{L}, \mathrm{Hb} 7.4 \mathrm{~g} / \mathrm{dL}$ and platelets $31 \times 10^{9} / \mathrm{L}$. A diagnosis of APL was made and ATRA and ATO were started. The patient had multiple comorbid conditions to include diabetes, hypertension, CAD, multiple pul- monary emboli and morbid obesity. She agreed to cryoprecipitate but refused all other blood products despite the $\mathrm{Hb}$ dropping to $6.7 \mathrm{~g} / \mathrm{dL}$. The patient deteriorated neurologically and died on day 2 of admission.

\section{Results}

We identified a total of 12 patients (9 published and 3 from our practice) with APL that have been treated (Table 1).,11-16 Seven were female, 4 male and one not known. Age range was 10 to 62 years; 2 high risk, 4 intermediate risk, 1 low risk and 5 unknown. 5 of the 12 patients died during induction. Three of the 5 deaths were high risk. Two patients were pregnant; one died along with fetal demise. All 5 patients that died had severe anemia reported as complication but without evidence of bleeding. This anemia appears to be secondary to myelosuppression. Four of the 7 surviving patients developed symptomatic anemia ( 3.7 to $7.9 \mathrm{~g} / \mathrm{dL}$ ); EPO was started in 3 of these patients after developing symptoms with a good response. A pregnant woman treated with ATRA alone developed fetal distress with a nadir $\mathrm{Hb}$ of $3.7 \mathrm{~g} / \mathrm{dL}$ and had EPO started on day 10; the patient responded achieved remission and had an uneventful delivery. One patient treated with ATRA and ATO without aggressive EPO support from initiation dropped his $\mathrm{Hb}$ to $5.2 \mathrm{~g} / \mathrm{dL}$, had a myocardial infarction and pulmonary edema but subsequently recovered. A 10 year old treated with ATRA and cytarabine had a nadir $\mathrm{Hb}$ of $4.4 \mathrm{~g} / \mathrm{dL}$ but responded to EPO started on day 10. A 62 year old patient treated with ATRA and ATO with EPO support from the start did not develop symptomatic anemia and had an uncomplicated induction and is in remission 10 years post treatment. 6 patients received ATRA or ATRA/ATO; 5 of whom developed symptomatic anemia. The one patient who did not was treated with EPO from day 1.

Table 1. Induction of acute promyelocytic leukemia patients belonging to the Jehovah's witness congregation.

\begin{tabular}{|c|c|c|c|c|c|c|c|c|}
\hline Year (ref) & $\begin{array}{l}\text { Age/ } \\
\text { sex }\end{array}$ & $\begin{array}{l}\text { Risk } \\
\text { status }\end{array}$ & Induction & $\begin{array}{l}\text { Initial Hb/ } \\
\text { Nadir Hb }\end{array}$ & $\begin{array}{l}\text { Supportive } \\
\text { care }\end{array}$ & Complications & $\begin{array}{l}\text { F/U } \\
\text { months }\end{array}$ & Death \\
\hline $1990(10)$ & $18 / \mathrm{F}$ & & Chemotherapy & $7.5 / 4.6$ & $\begin{array}{c}\text { Tranexamic acid, Aprotinin, } \\
\text { norethisterone }\end{array}$ & Anemia & & Yes \\
\hline $1996(11)$ & $28 / \mathrm{F}$ & Intermediate & ATRA & $6.2 / \mathrm{NR}$ & G-CSF, EPO & Pregnancy, Anemia & 12 & No \\
\hline $1997(19)$ & $10 / \mathrm{M}$ & Intermediate & ATRA higher dose/ Ara-C & 8.0/NR & EPO & Anemia & 9 & No \\
\hline $1998(12)$ & $28 / \mathrm{M}$ & High & Low dose ATRA Ara-C & $6.9 / 4.4$ & EPO & Anemia & & Yes \\
\hline 1999 & $17 / \mathrm{F}$ & & ATRA/IDA & NR & & & & No \\
\hline $2000(14)$ & $62 / \mathrm{F}$ & Intermediate & Low dose ATRA & $7.0 / 5.0$ & ЕPO & & 120 & No \\
\hline $2004(4)$ & & & ATRA, Dauno, Ara-C & NR & & & 32 & No \\
\hline 2007 & $39 / \mathrm{M}$ & Intermediate & Low dose ATRA/ATO & 8.6 & ЕPO & cardial infarction; Anemia & 36 & No \\
\hline 2013 & $71 / \mathrm{F}$ & High & ATRA/ATO & $6.6 / 3.3$ & EPO & Anemia & & Yes \\
\hline 2013 & $56 / \mathrm{F}$ & Low & ATRA/ATO & $11.8 / 7.9$ & Darbepoetin, EPO & Anemia, Angina & 12 & No \\
\hline 2014 & $59 / \mathrm{F}$ & High & ATRA/ATO & $7.4 / 6.7$ & ЕРО & Stroke & & Yes \\
\hline 2015 (15) & $28 / \mathrm{F}$ & & ATRA & $10.5 / \mathrm{NR}$ & & Pregnancy, Anemia & & Yes \\
\hline
\end{tabular}

ATRA, all-trans retinoic acid; ATO, Arsenic trioxide; Dauno, Daunorubicin; Ara-C, Cytarabine; 6-Thio, 6 Thioguanine; G-CSF, Granulocyte Colony Stimulating Factor; EPO, Erythropoietin; F/U, Follow up; Hb, Hemoglobin (grams/dL); NR, not reported.

Table 2. Acute promyelocytic leukemia induction suggestions for the Jehovah's witness patient.

Work up

Use pediatric tubes. CBC, CMP, D-dimers, PT, PTT, fibrinogen at admission. Fibrinogen and CBC three times a week. Chest X-ray. Echocardiogram. Bone marrow examination (aspirate, biopsy, flow, cytogenetics, FISH for PML-RAR alpha, PCR for PML-RARalpha). PICC line; NO central lines or invasive procedures (bronchoscopy, spinal tap). Day 14 marrow is NOT necessary. APL is a medical emergency - start ATRA asap.

Supportive care $\quad$ Allopurinol $300 \mathrm{mg}$ daily. Antibiotic prophylaxis - levofloxacin $500 \mathrm{mg}$ daily or similar antibiotic. Antifungal prophylaxis posaconazole $300 \mathrm{mg}$ daily, voriconazole $200 \mathrm{mg} 2$ daily or micafungin $50 \mathrm{mg}$ daily or a similar drug. Acyclovir $400 \mathrm{mg} 2$ daily or valacyclovir $1000 \mathrm{mg}$ daily.

Treatment of coagulopathy Keep fibrinogen above 150. Use cryoprecipitate if needed and agreeable. Amicar during the first 2 to 3 weeks if there is bleeding or profound thrombocytopenia

Prevention/treatment Daily weights - bedside scales only; Keep I/O matched - use diuretics for fluid retention or weight gain.

of APL differentiation Prednisone $0.5 \mathrm{mg} / \mathrm{Kg}$ for 14 days and taper if no evidence of DS. If WBC $>10,000$ at presentation or clinical evidence of DS, syndrome dexamethasone $10 \mathrm{mg}$ twice daily

Treatment ATRA $25 \mathrm{mg} / \mathrm{m}^{2}$ for 14 days. Increase to $45 / \mathrm{mg} / \mathrm{m}^{2}$ after 14 days if stable and no complications. ATO to be incorporated during consolidation

ATRA, all-trans retinoic acid; ATO, Arsenic trioxide. 


\section{Discussion}

A thorough discussion should be had with the patient regarding the nature of the disease, the high rate of curability, acceptable and unacceptable blood fractions. While the family members are generally a part of the discussion, the treating Oncologist/Hematologist should privately discuss with the patient his/her wishes in a life threatening circumstance to avoid peer pressure. ${ }^{7}$ Patients in this reported series have been treated from 1990 to 2014. Over that time, therapeutic agents available for APL as well as supportive care have changed dramatically. The most effective agents are not markedly myelosupressive but caution should be used to tide the patient through induction.

\section{Supportive care}

In 5 of 12 patients that died, there was symptomatic anemia with hemoglobin values as low as $3.6 \mathrm{~g} / \mathrm{dL}$ without evidence of bleeding and appears to be myelosuppression. This certainly was the reason for myelosuppression in our patients. Of the remaining seven, 4 patients developed symptomatic anemia that prompted use of EPO later in the course of treatment with response but substantial morbidity. Six of the 12 patients were treated with ATRA only or ATRA/ATO. Five of them developed symptomatic anemia; the one patient who did not develop symptomatic anemia was treated with EPO from day 1. From these observations it is apparent that the major cause of morbidity and mortality in Witnesses is non-hemorrhagic anemia and the goal from the onset should be to improve or prevent development of anemia. General supportive measures such as folic acid and iron therapy can be started at diagnosis. In one study intravenous iron was superior to oral iron supplementation for pre-operative stimulation of hemoglobin synthesis using EPO. ${ }^{17}$ Early institution of erythropoietin to increase or prevent a drop in hemoglobin will be beneficial and continued to maintain it above 10 . This is a consideration even if ATRA/ATO induction is being used as they are known to cause cytopenias. The dose of EPO used in leukemia or APL induction has been variable in the limited available literature. A reasonable dose of erythropoietin is 200 units/Kg and is adjusted based on the severity of the anemia.

Patients with profound thrombocytopenia and clinical evidence of bleeding, epsilon aminocaproic acid (amicar) has been used with success. Since APL is also a pro-coagulant condition, thrombosis is quite frequent. If amicar is used, careful monitoring for resolution of DIC should be undertaken after starting differentiating agents as it resolves quickly; at which point amicar can be discontinued. ${ }^{18}$

\section{Induction}

Using single agent ATRA might be the safest and most logical approach. Using both ATRA and ATO in combination causes leukocytosis in $>50 \%$ of patients. This may require use of hydroxyurea or anthracyclines to decrease the white count thereby causing unwanted myelosuppression. Also a full dose of ATRA can cause leukocytosis and predispose to DS. Single agent ATRA at a lower dose $\left(25 / \mathrm{M}^{2}\right.$-pediatric dose) followed by increasing to full dose after 14 days if there are no complications may be better tolerated. ATRA can be continued until hematologic remission is achieved. Prophylactic steroids to prevent DS at least during the first 2 weeks would be helpful to avoid unnecessary complications. It may not be necessary to use ATO during induction but can be effectively incorporated during consolidation. The goal during induction in these patients is to reverse the DIC, prevent early deaths and achieve hematologic remission without blood product support.

\section{Conclusions}

Jehovah's Witnesses with APL are a unique population due to their refusal to accept blood product support. The biggest hurdle for cure is early death during induction. Patients who survive induction achieve hematologic and molecular remission and in all likelihood are cured. Anemia is the most frequent cause of morbidity and mortality. We suggest aggressive use of erythropoietic growth factors and supportive care to treat anemia. Single agent ATRA during induction followed by incorporation of ATO during consolidation may be the most logical approach to minimize complications during induction. Based on our own experience and published literature, we outline suggestions regarding strategies that may be practical especially during induction to prevent early deaths (Table 2).

\section{Suggested outline: recommendations}

The following recommendations are proposed: i) discuss with the patient regarding APL and the excellent outcome; ii) acceptable/unacceptable blood products; iii) blood draws in pediatric tubes; iv) folic acid and intravenous iron; v) erythropoeitin 200 $\mathrm{u} / \mathrm{kg}$ three times a week to start at the begin- ning of induction; vi) epsilon aminocaproic acid (Amicar) in patients with platelets $<10,000$ or clinical evidence of bleeding; can be discontinued after 14 to 21 days; vii) prednisone $0.5 \mathrm{mg} / \mathrm{kg}$ for 14 days and taper if no evidence of differentiation syndrome; viii) ATRA $25 \mathrm{mg} / \mathrm{M} 2$ for 14 days; increase to $45 \mathrm{mg} / \mathrm{M} 2$ if no complications (in patients $<65$ and without comorbid conditions) till hematologic remission; ix) avoid ATO during induction; can be incorporated during consolidation.

\section{References}

1. Sharp D. Jehovah's Witnesses' blood policy. Lancet 2000;356:8.

2. Cullis JO, Duncombe AS, Dudley JM, et al. Acute leukaemia in Jehovah's Witnesses. Br J Haematol 1998;100: 664-8.

3. Goldberg SL, Chan CS, Dawkins FW, et al. Should Jehovah's witnesses be denied intensive chemotherapy for acute leukemia? N Engl J Med 1990; 322:777-8.

4. Laszlo D, Agazzi A, Goldhirsch A, et al. Tailored therapy of adult acute leukaemia in Jehovah's Witnesses: unjustified reluctance to treat. Eur J Haematol 2004;72:264-7.

5. Jillella AP, Kolhe RB, Awan F, et al. A successful model to decrease early deaths in acute promyelocytic leukemia (APL) through the use of a simplified algorithm and expert support. Blood 2013;122:5597.

6. Lehmann S, Ravn A, Carlsson L, et al. Continuing high early death rate in acute promyelocytic leukemia: a population-based report from the Swedish Adult Acute Leukemia Registry. Leukemia 2011;25:1128-34.

7. Marsh JC, Bevan DH. Haematological care of the Jehovah's Witness patient. Br J Haematol 2002;119:25-37.

8. Muramoto O. Bioethical aspects of the recent changes in the policy of refusal of blood by Jehovah's witnesses. BMJ 2001;322:37-9.

9. Dainer PM, Knupp CL, Sartiano GP. Low-dose cytosine arabinoside as an alternative treatment for acute leukemia in Jehovah's Witnesses. Am J Hematol 1992;40:156-7.

10. Cullis JO, Smith AG. Jehovah's Witnesses with leukaemia. Lancet 1990;336:1075-6.

11. Lin CP, Huang MJ, Liu HJ, et al. Successful treatment of acute promyelocytic leukemia in a pregnant Jehovah's Witness with all-trans 
retinoic acid, rhG-CSF, and erythropoietin. Am J Hematol 1996;51:251-2.

12. Menendez A, Svarch E, Martínez G, Hernández P. Successful treatment of acute promyelocytic leukemia using alltrans retinoic acid and erythropoietin in a Jehovah's Witness boy. Ann Hematol 1998;76:43-4.

13. Mazza P, Palazzo G, Amurri B, et al. Acute leukemia in Jehovah's Witnesses: a challenge for hematologists. Haematologica 2000;85:1221-2.

14. Kennedy GA, Marlton P, Cobcroft R, Gill D. Molecular remission without blood product support using all-trans retinoic acid (ATRA) induction and combined arsenic trioxide/ATRA con- solidation in a Jehovah's Witness with de novo acute promyelocytic leukaemia. Br J Haematol 2000;111: 1103-5.

15. Biscoe A, Kidson-Gerber G. Avoidable death of a pregnant Jehovah's Witness with acute promyelocytic leukaemia: ethical considerations and the internal conflicts and challenges encountered by practitioners. Intern Med J 2015;45: 461-2.

16. Keane C, Marlton P, Cobcroft R, Gill D. Treatment of acute promyelocytic leukaemia in the Jehovah's Witness population. Ann Hematol 2011;90:35960.

17. Rohling RG, Zimmermann AP,
Breymann C. Intravenous versus oral iron supplementation for preoperative stimulation of hemoglobin synthesis using recombinant human erythropoietin. J Hematother Stem Cell Res 2000;9:497-500.

18. Keane TJ, Gorman AM, O'Connell LG, Fennelly JJ. Epsilon-Amino-caproic acid in the management of acute promyelocytic leukaemia. Acta Haematol 1976;56:202-4.

19. Fujita H, Maruta A, Koharazawa H, et al. Successful treatment of a Jehovah's Witness with acute promyelocytic leukemia. Int J Hematol 1997;65:415-6. 